\title{
Comparative Evaluation of Extrusion of Apical Debris and Irrigant from Curved Root Canals Using Three Different Ni-Ti Instruments with Conventional Needle Irrigation Methods - An In Vitro Study
}

\author{
Baljeet Singh Hora ${ }^{1}$, Yadnesh Arun Dondulkar², Vaibhav Suresh Jain³, \\ Shailendra Kumar Sahu ${ }^{4}$, Nitin Prakash Chand Jogad ${ }^{5}$, Neetu Maurya ${ }^{6}$ \\ 1, 2, 3, 4,6 Department of Conservative Dentistry and Endodontics, Chhattisgarh Dental College and Research Institute, \\ Sundra, Rajnandgaon, Chhattisgarh, India, ${ }^{5}$ Department of Conservative Dentistry and Endodontics, Swargiya \\ Dadasahebh Kalmegh Smruti Dental College and Hospital, Nagpur, Maharashtra, India.
}

\section{ABSTRACT}

\section{BACKGROUND}

Extrusion of debris, bacteria, and irrigant effect the inter-appointment flare ups and post-operative outcome of the endodontic treatment. So, it is necessary to make every effort to minimize such extrusion during cleaning and shaping of the canals. The present study was done to compare and evaluate debris and irrigant extrusion from curved root canals using different Ni-Ti systems.

\section{METHODS}

30 mesial roots of mandibular molars were used in this study. Crown were decoronated, working length and initial apical diameter was established. $1.5 \%$ agar gel model was used in this study. Samples were assigned randomly into 3 groups (n $=10$ teeth per group). ProTaper Next, One Shape, FANTA AF BLUE F ONE files were used according to the manufacturer's instructions for canal instrumentation. Apically extruded debris and irrigant was computed after the biomechanical preparation and their comparative analysis for each of the instruments and experimental models was performed.

\section{RESULTS}

Statistically significant difference was found between the three experimental groups. $(\mathrm{P}<.05)$.

\section{CONCLUSIONS}

All the instruments produced apically extruded debris and irrigant, but least was seen with FANTA AF BLUE F ONE and maximum with One Shape among the experimental groups.

\section{KEY WORDS}

Apical Debris, Irrigant, NiTi Files
Corresponding Author: Dr. Yadnesh Arun Dondulkar, Department of Conservative Dentistry, Chhattisgarh Dental College and Research Institute, Sundra, Rajnandgaon, Chhattisgarh, India.

E-mail:ydondulkar@gmail.com

DOI: $10.14260 / \mathrm{jemds} / 2021 / 595$

How to Cite This Article:

Hora BS, Dondulkar YA, Jain VS, et al. Comparative evaluation of extrusion of apical debris and irrigant from curved root canals using three different NI-TI instruments with conventional needle irrigation methods - an in vitro study. J Evolution Med Dent Sci 2021;10(34):29202923, DOI: 10.14260/jemds/2021/595

Submission 22-05-2021,

Peer Review 16-07-2021,

Acceptance 22-07-2021,

Published 23-08-2021.

Copyright (C) 2021 Baljeet Singh Hora et al. This is an open access article distributed under Creative Commons Attribution License [Attribution 4.0 International (CC $B Y 4.0)]$ 


\section{BACKGROUND}

Endodontics is a discipline of dentistry that involves the aetiology, diagnosis, prevention, and treatment of "pulpal disorders".1 Favourable outcome of root canal treatment depends on a triad that is proper access cavity preparation, thorough cleaning and shaping, and 3-D filling of the canal space. Endodontic failure occurs when the treatment protocol followed is below standard. Endodontic failure is nothing but the persistence of symptoms, periapical pathology, and periapical radiolucency post-treatment. Endodontic failure may be attributed to various procedural errors like missed canals, under and over instrumentation, inadequate seal in root canal space, extrusion of debris, irrigants, and canal filling material in the periapical region. ${ }^{2}$

Flare-ups after root canal treatment have been observed to occur at a rate of $1.4 \%-16 \%{ }^{3}$ Many factors that affect the inter appointment flare-ups and post-operative pain are like an error in working length determination, instrumentation techniques, apical debris extrusion, and over instrumentation. During biomechanical preparation of the root canal, dentin chips, pulp tissue, microorganism, and irrigants may be expelled in the periapical region. It has been proved that noncontaminated and contaminated debris when forced peri apically can trigger an inflammatory reaction. Various studies have proved that the extrusion of debris may be affected by various reasons like different canal curvature, working length, difference in instrument kinematics, apical diameter, amount, and type of irrigants used, number of files, different instrumentation technique, pre-flaring coronal third, instrument design and irrigation system used. Hence, it is highly essential to prevent debris extrusion through the selection of proper instruments and techniques.

Literature is evident that various researches have been done to minimize extrusion of debris and irrigant like advances in apex locators, modification in instrument design, use of side vented needle, and negative irrigation system.

Studies have proved that various changes in the $\mathrm{Ni}$ - $\mathrm{Ti}$ rotary design like ProTaper Next (PTN), M two, One Shape, etc. have been done to minimize the debris extrusion.

However, no technology or method has proved to be full proof in preventing the extrusion of debris and irrigant peri apically, only the extent varies. Till date, no study had been found in research databases that evaluated the amount of apical extrusion of debris and irrigant comparing PTN, One Shape with FANTA AF BLUE F ONE file. So, this study aimed to evaluate and compare the effect of three continuous rotary $\mathrm{Ni}$ Ti instruments, using three different irrigation methods on apical extrusion of debris and irrigant in curved root canals.

\section{METHODS}

\section{Preparation of the Teeth}

Thirty mesial roots of molars that had been recommended for extraction for a variety of reasons from December 2019 to February 2020, at Chhattisgarh Dental College and Research Institute, Rajnandgaon were utilized in the study. Fully formed mesial roots of mandibular molar having curvature angles from $10^{\circ}$ to $20^{\circ}$, and separate canals were selected for the study. A diamond disk was used to slice the mesial roots at the cementoenamel junction (to generate root specimens with a standardized size of $13 \mathrm{~mm}$ ) (Fig 1). Curvature angle was measured using ImageJ software (Fig 2). The initial width of the apical foramen was determined by inserting a \#15 K-type file (Mani) so that it will penetrate the canal snugly, and envisioning its tip leaving the apical foramen, and the working length was then adjusted to be $1 \mathrm{~mm}$ shorter than the measured length.

This method was used to determine the working length of all the specimens. Samples were divided into three groups. In group A, biomechanical preparation was done with ProTaper Next files, in group B it was done with One Shape file and in group $\mathrm{C}$ it was done with FANTA AF BLUE F ONE file. Canals not fulfilling the criteria were discarded from the research and replaced with new specimens.
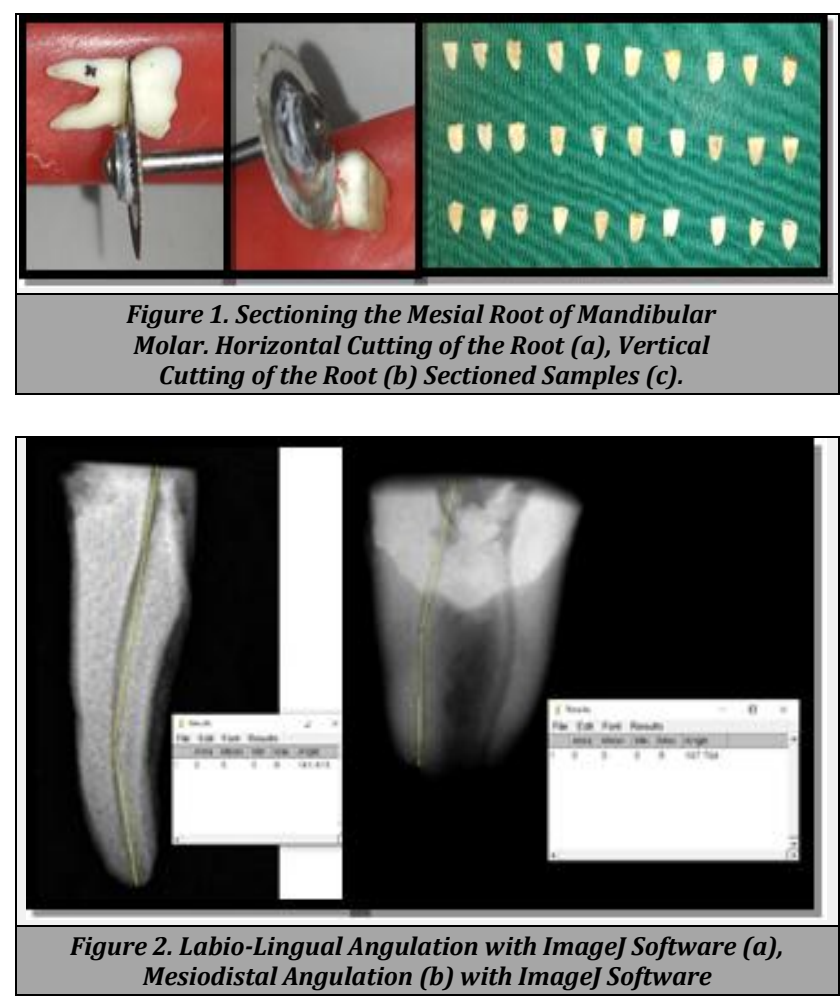

\section{Test Apparatus}

$1.5 \%$ agar gel model was used in this study as described in previous studies to simulate periapical tissue. The root specimen was encased with Teflon tape, exposing the apical foramen and coronal surface and weighed using a microbalance (SHIMADZU AUW - 220D) [Fig 3 (a)] having an accuracy of $0.01 \mathrm{mg}$.

Agar solution was prepared in a $500 \mathrm{ml}$ flask containing $100 \mathrm{ml}$ of filtered distilled water and $1.5 \mathrm{~g}$ agar-agar powder (Weissmill) to obtain $1.5 \%$ concentration. $3 \mathrm{~mL}$ of $1.5 \%$ agar gel was infused into each tube. The root was pushed through the orifice, and a rubber dam sheet was placed as in clinical procedure to isolate the specimen. The tube was inverted to immerse the tooth in agar until the agar congealed [Fig 4 (a)].

The apparatus was weighed [Fig 3 (b)], and the weight of the assembly without the specimen was computed. The apparatus was then put in an opaque bottle, preventing the operator from having any direct manual or visual contact with it during the operation. 

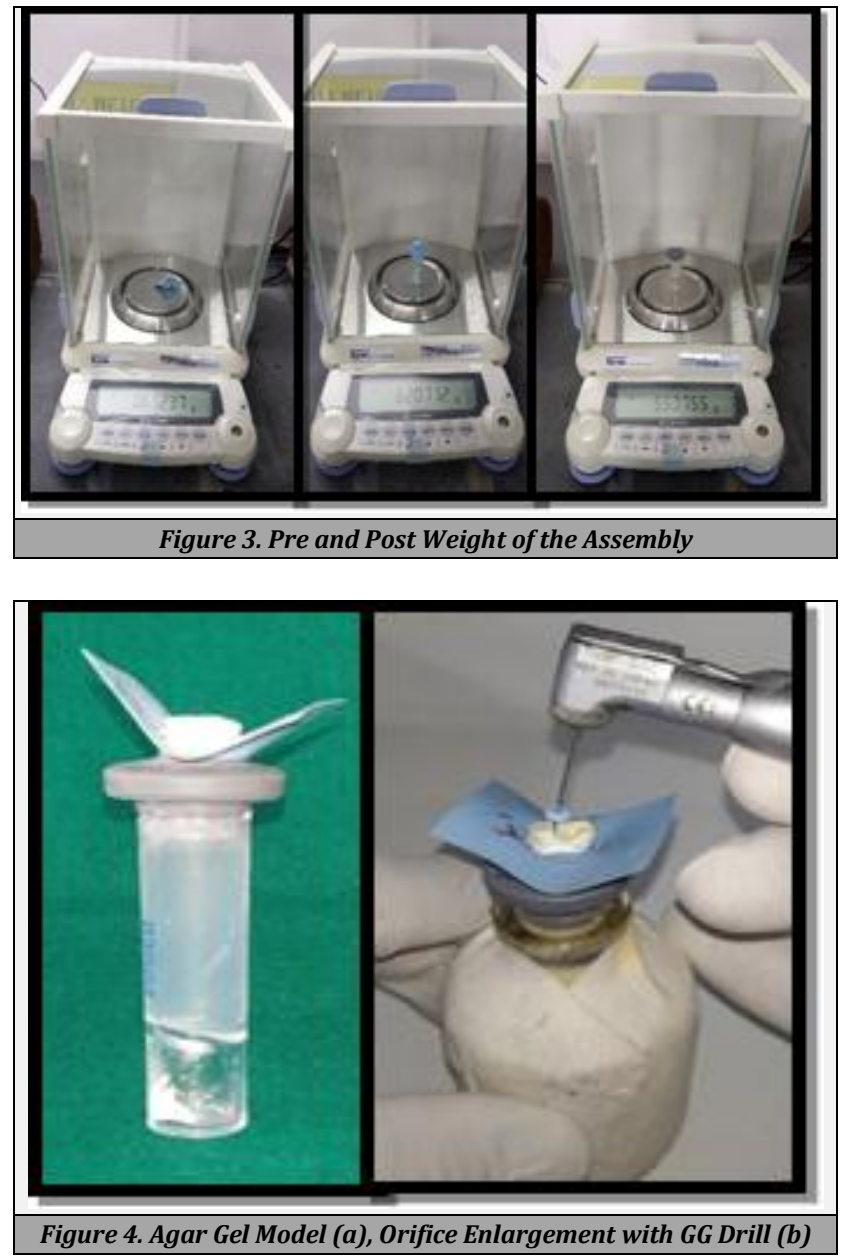

\section{Procedure}

In all the groups, coronal flaring in the canals was done using Gates-Glidden drills \#4, \#3, and \#2 (Mani) "[Fig 4(b)].8" The root canals were initially flooded with $1 \mathrm{ml} 3 \% \mathrm{NaOCl}$ (Prime). Glide path was prepared by manual method with \#8, \#10, and \#15 ISO $2 \%$ files (Mani) in a push and pull motion keeping procedure standard for all. The Endomotor (Endoking) was adjusted for each instrument according to the manufacturer's instruction. In group A, all the canals were prepared using ProTaper Next up to size X2 (25.06), RPM 300 and torque 200 gcm. Similarly, in group (B) One Shape (25.06) was used till it reached the working length at $400 \mathrm{RPM}$, in group (C) FANTA AF BLUE F One F5 (25.06) was used till it reaches working length at $500 \mathrm{RPM}$ and $2.6 \mathrm{~N}$ torque. Regardless of the system to which it belonged, each instrument was used for the preparation of up to three canals and then discarded.

Canal was irrigated with $1 \mathrm{~mL}$ of saline using a side vented dental needle (30 gauge) during shaping of each third of the root canals or after every file change. During the administration of the irrigant, a slight (1 - $2 \mathrm{~mm}$ ) steady apicalcoronal movement of the needle was maintained. After each motion and canal irrigation cycle, patency was established across all groups by putting a \#10K type file up to $1 \mathrm{~mm}$ further than apical foramen. For each group, final irrigation was 3 cycles of $2 \mathrm{~mL} 3 \% \mathrm{NaOCl}$ (Prime) for 20 seconds each with a 30-gauge single side vented needle (Neoendo endo irrigation needles). During biomechanical preparation, the terminals of all activation devices as well as the irrigation needle, were placed as deeply as practical apically before binding, but not more than $1 \mathrm{~mm}$ short of working length. The canal was dried with 25.06 paper points. The tooth and Teflon tape were removed from the tube. After removing the tooth, the apparatus was weighed [Fig 3(c)], and the weight of the apically extruded debris and irrigant was estimated by subtracting the pre-procedure weight from the postprocedure weight. ." $^{\prime \prime}$

\section{Statistical Analysis}

Continuous data were summarized as Mean \pm SD (standard deviation). Quantitative data was analyzed by mean, SD, unpaired t-test. Statistical significance $\mathrm{P} \leq 0.05$ is significant. Statistics software used was Statistical Package for Social Sciences (SPSS 16.0)

\section{RESULTS}

\begin{tabular}{|c|c|c|c|c|}
\hline \multicolumn{5}{|c|}{ Apically Extruded Debris and Irrigant (g) } \\
\hline Groups & Min & Max & Mean & SD \\
\hline PTN & 0.010573 & 0.017147 & 0.014 & 0.0032 \\
\hline One shape & 0.015057 & 0.03034 & 0.022 & 0.005 \\
\hline $\mathrm{F}$ one & 0.00564 & 0.00945 & 0.0077 & 0.0015 \\
\hline \multicolumn{5}{|c|}{$\begin{array}{c}\text { Table 1. Depending on the Group, the Amount of } \\
\text { Apically Extruded Debris and Irrigant }\end{array}$} \\
\hline
\end{tabular}

There was a statistically significant difference between the three experimental groups. $(\mathrm{P}<.05)$. Among all the groups, least extrusion was observed in the FANTA AF BLUE F ONE group used in combination with conventional irrigation. The ranking from least to most extrusion was as follows: FANTA AF BLUE F ONE < ProTaper Next < One Shape.

\section{DISCUSSION}

The null hypothesis was rejected considering that there was a significant difference in apical extrusion of debris and irrigant between the three $\mathrm{Ni}$-Ti systems with conventional needle irrigation. The variables that generally impact debris extrusion were used as sampling frame in this study. We examined the apically extruded debris of three distinct file systems with various designs, manufacturing techniques, and file numbers. Mesial roots of mandibular molars with $10^{\circ}-20^{\circ}$ curvature were selected as it has been found in previous studies that extrusion was less in straight canals which can lead to an inaccurate conclusion. It is generally accepted that an analytical balance can reveal variations in apically extruded debris and irrigant between the groups. The technique of Lu et al. (2013) was updated in this work to assess debris and irrigant extrusion. Because either can produce an interappointment flare-up, zero attempt was made to separate debris from irrigant. In clinical settings, the presence of periapical tissue and even granulation tissue in chronic periapical periodontitis may provide resistance to apically extruded debris and irrigant. Because $1.5 \%$ agar has a comparable density to periapical tissues (agar: $1045 \mathrm{~kg} \mathrm{~m} 3$ vs. human tissue: $1000-1100 \mathrm{~kg} \mathrm{~m} \_3$ ), it was employed to mimic periapical tissue in this research. Because the lesions (e.g. periapical granulomas or cysts) are of various sizes and forms, the agar gel at the apex was roughly $1 \mathrm{~cm}$ thick. As a result, 
determining the thickness of the agar gel at the apex was challenging. The specimen tubes were put in opaque-coloured vials with mouths that were equal in diameter to the tubes, permitting only view of the canal entrances during shaping, much like in a real clinical setting, and preventing the operator from manipulating the results.

Arslan D et al. (2018) compared the ProTaper Next file system and the One Shape file system with respect to extrusion of debris and found multiple files system extruded less debris. In contrast, present extrusion among FANTA AF BLUE F ONE group was less when compared with ProTaper Next. However, this difference may have been found due to different cross sections. The taper of the instrument employed has also been linked to debris extrusion, with some research suggesting that files with a greater taper are more likely to extrude debris. Despite the fact that the roots were instrumented with open apices, the 1.5 percent agar gel technique was employed in this investigation. Because modelling of bone or periodontal ligament employing some form of physical barrier might trap material that would otherwise be ejected, affecting the results validity, this methodologic alternative is acceptable.

\section{CONCLUSIONS}

Considering the limitations of the study, it was concluded that when the instruments from the FANTA AF BLUE F ONE and One Shape single file systems were used on the same working lengths during instrumentation of moderately curved canals, the levels of dentin debris extrusion were significantly different.

Data sharing statement provided by the authors is available with the full text of this article at jemds.com.

Financial or other competing interests: None.

Disclosure forms provided by the authors are available with the full text of this article at jemds.com.

\section{REFERENCES}

[1] Grossman LI, Seymour O, Del Rio CE. Prteparation of root canal. Chap - 11. Endodontic Practice. 11th edn. Indian edn. Dadar, Bombay: Varghese Publishing House 1988: p. 187-8.

[2] Cohen S. Cohen's Pathways of Pulp. 9th edn. St. Louis: Elsevier 2006: p. 918-34.

[3] Siqueira Jr JF, Rôças IN, Favieri A, et al. Incidence of postoperative pain after intracanal procedures based on an antimicrobial strategy. J Endod 2002;28(6):457-60.

[4] Myers GL, Montgomery S. A comparison of weights of debris extruded apically by conventional filing and Canal Master techniques. J Endod 1991;17(6):275-9.

[5] Mendonça D, de Moura JD, Bueno CEDS, et al. Extrusion of debris from curved root canals instrumented up to different working lengths using different reciprocating systems. J Endod 2019;45(7):930-4.

[6] Lu Y, Wang R, Zhang L, et al. Apically extruded debris and irrigant with two Ni-Ti systems and hand files when removing root fillings: a laboratory study. Int Endod J 2013;46(12):1125-30.

[7] Leonardi LE, Atlas DM, Raiden G. Apical extrusion of debris by manual and mechanical instrumentation. Braz Dent J 2007;18(1):16-19.

[8] Topçuoğlu HS, Üstün Y, Akpek F, et al. Effect of coronal flaring on apical extrusion of debris during root canal instrumentation using single-file systems. Int Endod J 2016;49(9):884-9.

[9] Altundasar E, Nagas E, Uyanik O, et al. Debris and irrigant extrusion potential of 2 rotary systems and irrigation needles. Oral Surg Oral Med Oral Pathol Oral Radiol and Endod 2011;112(4): e31-e5.

[10] Schneider SW. A comparison of canal preparations in straight and curved root canals. Oral Surg Oral Med Oral Pathol 1971;32(2):271-5.

[11] Haupt F, Meinel M, Gunawardana A, et al. Effectiveness of different activated irrigation techniques on debris and smear layer removal from curved root canals: a SEM evaluation. Aust Endod J 2020;46(1):40-6.

[12] Keskin C, Yilmaz SÖ, Inan U, et al. Postoperative pain after glide path preparation using manual, reciprocating and continuous rotary instruments: a randomized clinical trial. Int Endod J 2019;52(5):579-87.

[13] Arslan D, Kustarci A. Efficacy of photon-initiated photoacoustic streaming on apically extruded debris with different preparation systems in curved canals. Int Endod J 2018;51(Suppl 1):e65-e72. 